\section{Palaeo and present channel of Assi river, Uttar Pradesh, India}

\author{
Mallikarjun Mishra ${ }^{1, *}$, K. N. Prudhvi Raju ${ }^{1}$ and \\ P. V. Raju ${ }^{2}$ \\ ${ }^{1}$ Department of Geography, Institute of Science, \\ Banaras Hindu University, Varanasi 221 005, India \\ ${ }^{2}$ Water Resources Assessment Division, National Remote Sensing \\ Centre, Indian Space Research Organisation, Hyderabad 500 037, India
}

The Assi river in Varanasi, Uttar Pradesh, India, is now a small, local, ephemeral floodplain tributary of River Ganga, with a length of about $8 \mathrm{~km}$ and catchment area of about $22 \mathrm{~km}^{2}$. It has also turned into a filthy drain. There are evidences in the form of palaeochannels, through patterns of water bodies and settlements along them, to suggest the origin of Assi river near Allahabad flowing through a distance of about $120 \mathrm{~km}$ up to Varanasi to meet the Ganga. There is also the possibility that Assi started as a takeoff from River Ganga and flowed as a Yazoo stream. Through on-screen digitization from high and medium-resolution remote sensing data-BHUVAN and Google Earth, CORONA aerial photographs, IRS P6 LISS-IV, Landsat 1, 3, 5, 7, 8- and a number of cross profiles from SRTM $30 \mathrm{~m}$ digital elevation model (DEM), palaeochannel of Assi has been delineated. Also, a $1 \mathrm{~m}$ DEM was generated for the present Assi catchment area from about 5000 DGPS points to present proof that the present Assi is a misfit in once a wider valley shaped by heavy discharge coming from a greater length of channel and a larger catchment area.

Keywords: Catchment area, flood plains, palaeochannel, remote sensing.

FLOODPLAINS of large to medium rivers, though seem to be featureless contain many forms and features of microrelief - natural levees, point bars, flood basins - and some with very insignificant or no relief at all-oxbow lakes, meander cut-offs, meander scrolls, abandoned and buried channels; the former cannot be made out unless the scale of the map is large enough and the contours are at very short intervals of $1 \mathrm{~m}$ or so, and the latter group of features are neither found in general-purpose maps nor contours of even $1 \mathrm{~m}$ interval can clearly show such features on maps. Recently buried palaeochannels in floodplains are difficult to be discerned by even field traverses. In order to determine and delineate such features in the plains, aerial photographs and satellite imagery are indispensable ${ }^{1}$.

Palaeochannels do not carry water, except during peak flood periods ${ }^{2}$. The abandoned and silted channels of the recent past forming the surface of the present floodplain

*For correspondence. (e-mail: mallikarjungeobhu2016@gmail.com) can be clearly seen and mapped using remote sensing data; but, where such channels are not clear, image patterns of some land-use details like ponds, settlements and agricultural fields controlled and conditioned by the presence of once active channels help in interpreting the existence of palaeochannels ${ }^{3}$.

The Sarasvati, once a famous river in India referred to in the Vedic texts which disappeared long ago, has been initially traced through interpretation of aerial photographs ${ }^{4}$ and satellite images ${ }^{5-7}$. In a memoir published by the Geological Society of India on the 'Vedic Sarasvati, ${ }^{8}$,

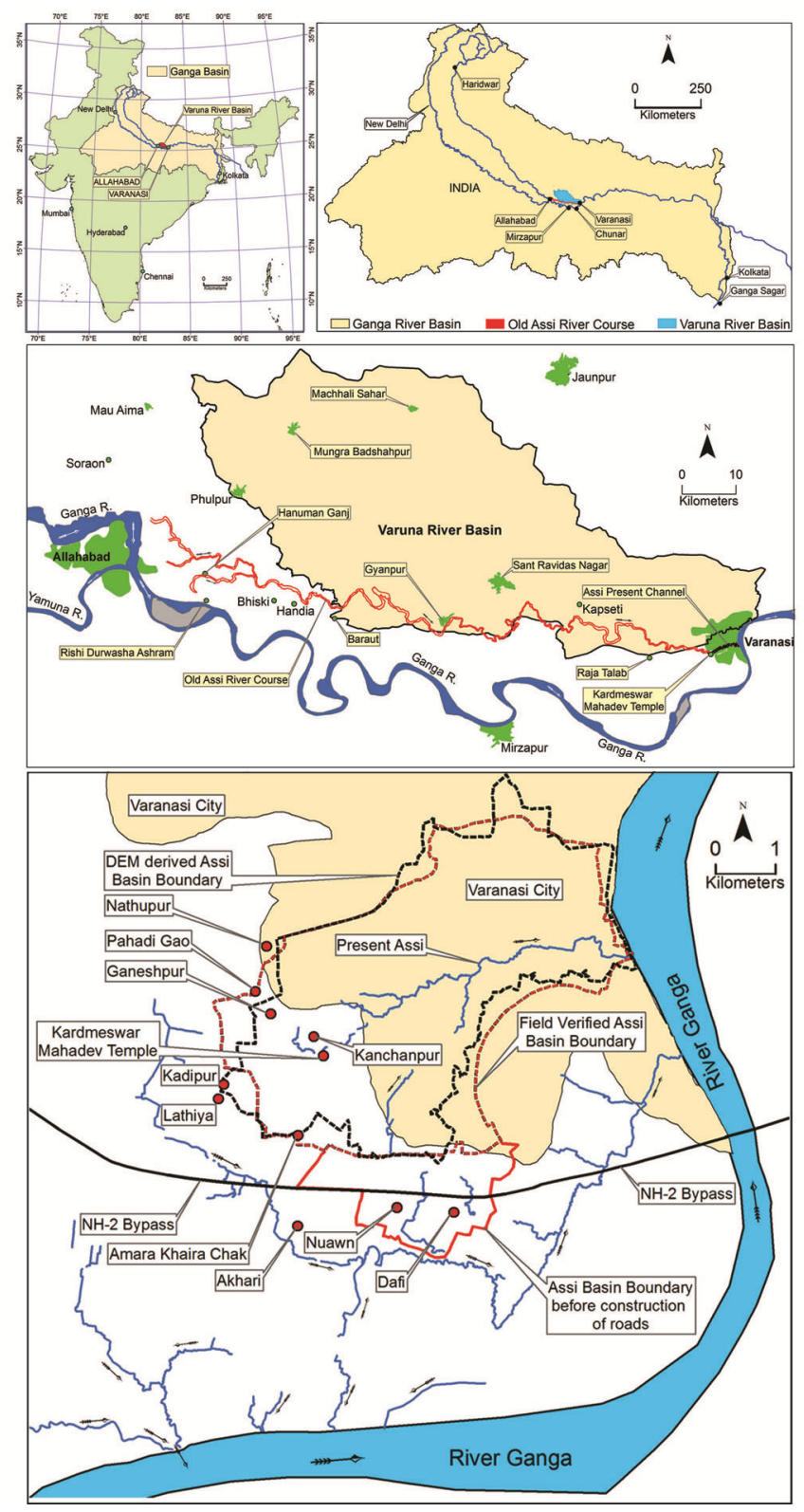

Figure 1. (Top) Location map showing Assi river palaeochannel (red), Varuna river basin within the Ganga basin and some important places. (Bottom) Present Assi river basin boundary derived from DEM (black dashed line) and field-verified boundary of post-NH-2 bypass road construction (red dashed line) and pre-NH-2 bypass road construction (red solid line) with streams within and south of the basin. 

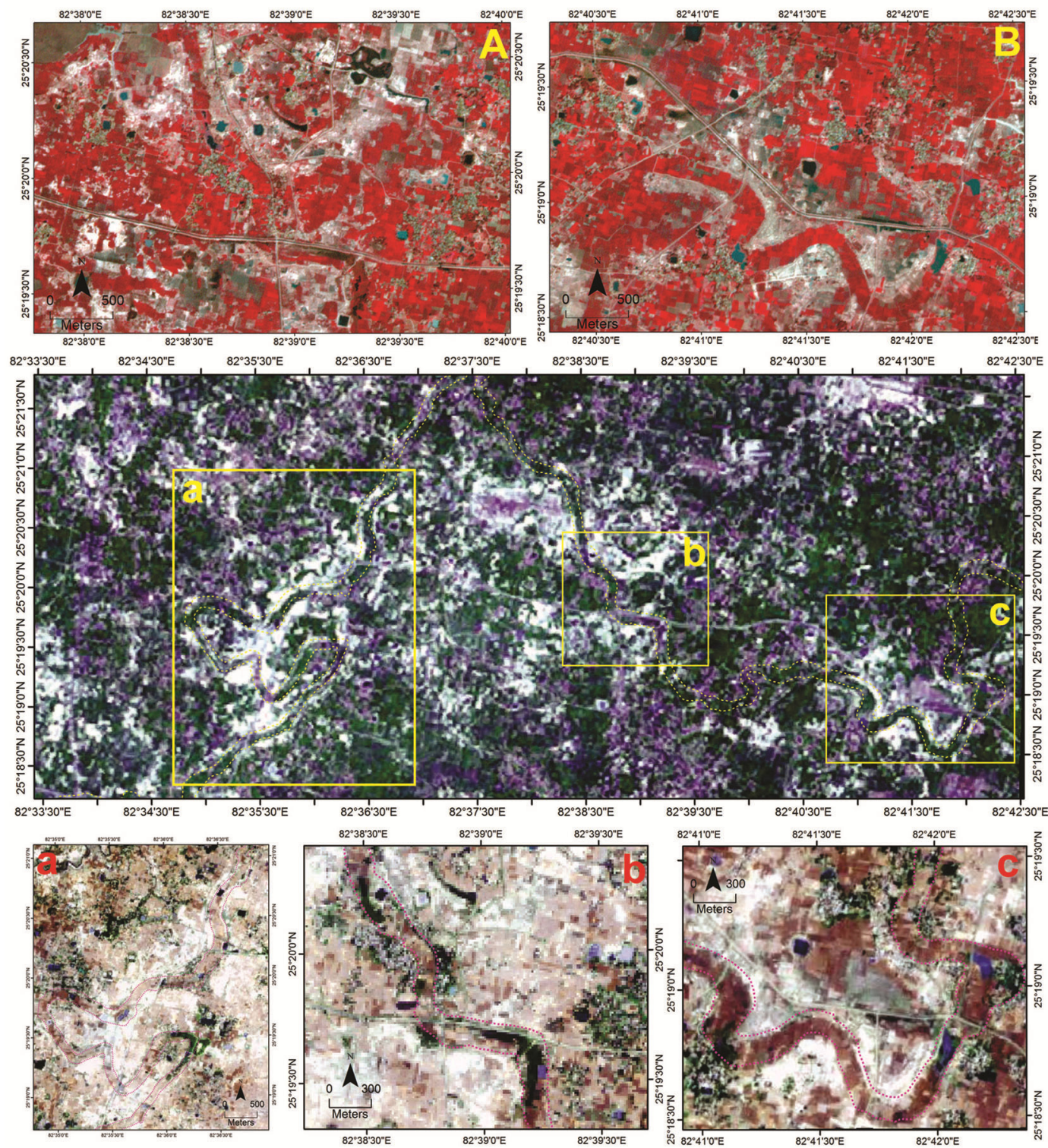

Figure 2. A and B satellite images of IRS-P6 LISS IV (top). Satellite images from BHUVAN (middle and bottom) showing palaeochannel segments (marked as yellow and red dotted lines) of old Assi river course.
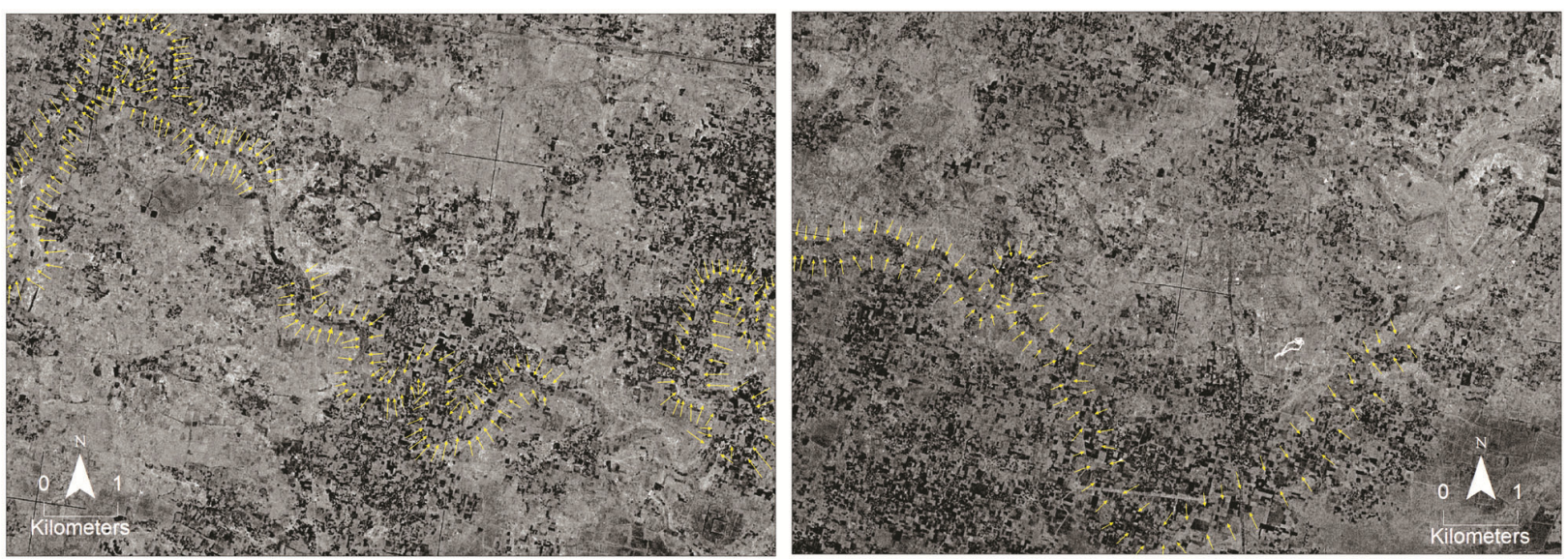

Figure 3. The Assi palaeochannel segments (partly indicated by arrows where the channel visibility is somewhat poor) as seen in CORONA aerial photographs. 

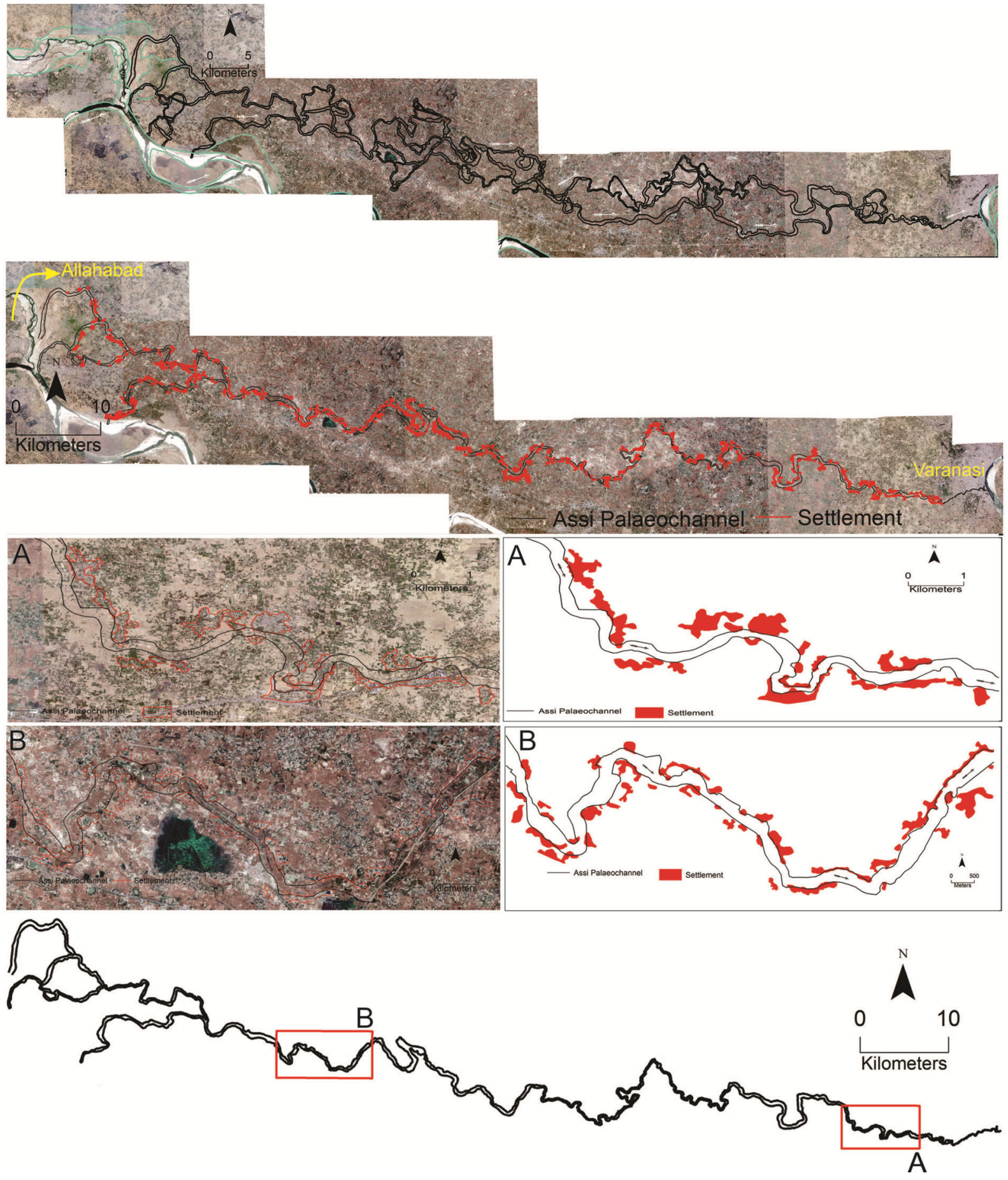

Figure 4. (Top) The Assi palaeochannel network (black) and the Ganga channel (blue) superposed over satellite image (Google Earth). Villages (red polygons) along the Assi palaeochannel network (black). A and B are enlarged views of satellite images of areas indicated in red blocks and their corresponding maps.

there are several research papers throwing light on the evolutionary history of the Sarasvati using optical and radar remote sensing data. As River Sarasvati is buried under deep sediments, its surface impressions are fuzzy and hence there was a need to adopt geophysical methods to trace and infer about its existence. Satellite data with synoptic coverage of large areas proved fitting to trace palaeochannels and distributaries of great lengths covering large areas easily ${ }^{2,6,9-11}$.

Of late, on account of many programmes initiated by the National Ganga River Basin Authority (NGRBA) in India, there is a spurt of interest on the Varuna and Assi rivers, two of the many 'floodplain' tributaries joining River Ganga near the city of Varanasi in Uttar Pradesh 

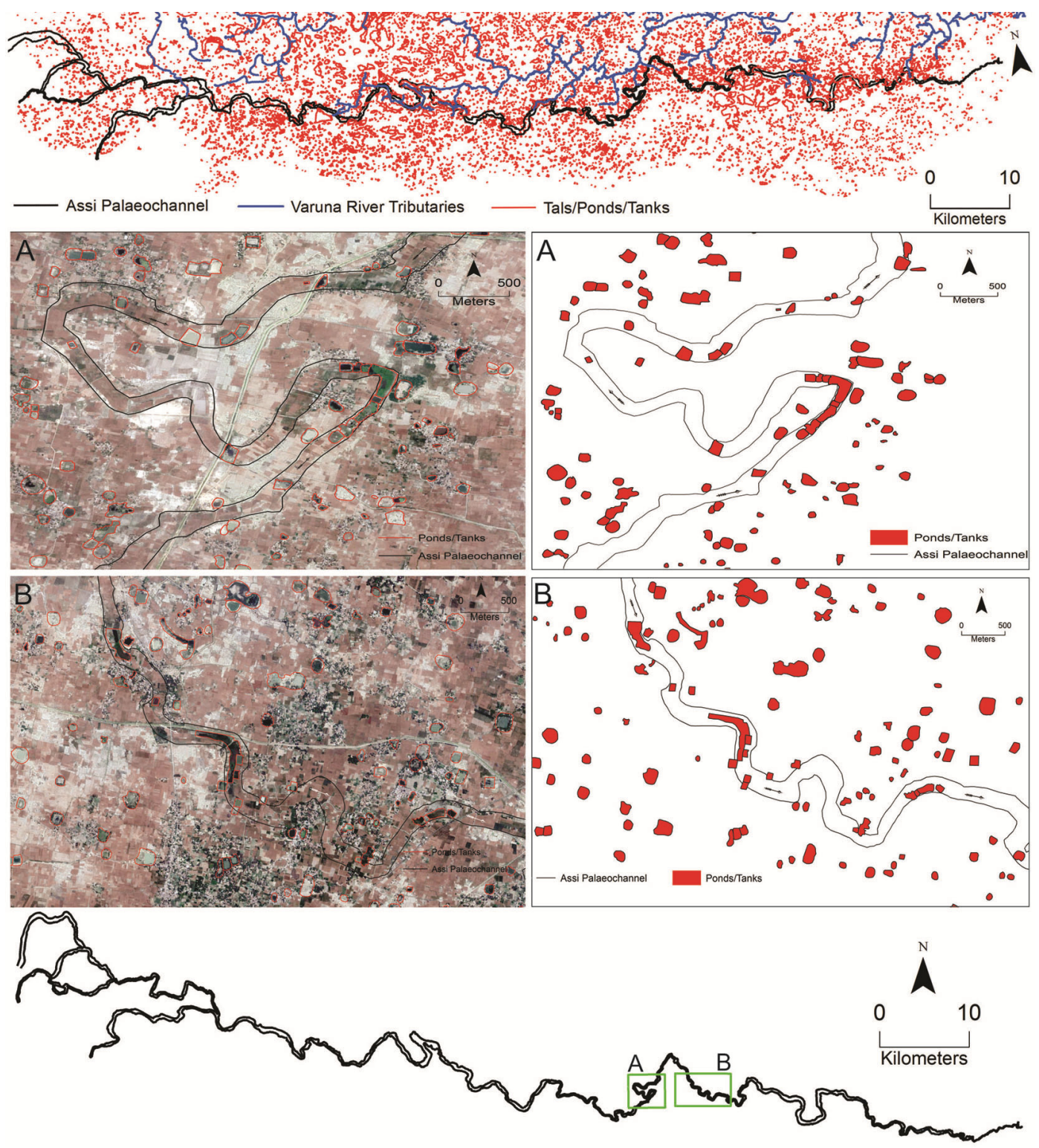

Figure 5. (Top) Large basins/depressions (tals), ponds/tanks (red hollow polygons) along and on either side of the Assi palaeochannel. (Bottom) Enlarged views of satellite images and maps (A and B) of areas marked in the index map showing ponds/tanks (red polygons).

(UP), India. Varanasi, the world's oldest living city and a place of religious importance for Hindus of the world on the left bank of River Ganga, is situated between the Varuna river in the north and Assi river in the south (Figure 1). Both these small tributaries of the Ganga once carried pristine pure waters like many other rivers of the world in the past. Though Assi is now a small, local, ephemeral stream compared to the Varuna, it is a cynosure of all eyes and an eye-sore as several pollutants flow through it to ultimately enter into the Ganga River. Palaeochannels are known to be reservoirs of good groundwater sources ${ }^{9,12}$. The present study is especially important in the context of groundwater resources in this region of India because the palaeochannels of Assi can be found in a wide belt and are considerably long measuring between 172 and $187 \mathrm{~km}$ in length.

The questions connected with the Assi are regarding the place of its origin, status in terms of length and its catchment area. Demarcation of the catchment boundary of the Assi river is difficult because of two reasons: (i) it is in a floodplain with very low total and relative relief, and (ii) most of the catchment surface is covered by urban built-up landscape. The catchment boundary of the Assi is of particular importance because there is a need to evaluate the contribution of storm-water flow and pollutants into its channel, which ultimately get into the Ganga River, especially fouling the famous Ganga ghats of Varanasi city. This study, besides presenting proof of 


\section{RESEARCH COMMUNICATIONS}

existence of a palaeochannel of the Assi river between Allahabad and Varanasi dispels some doubts about the present course of the Assi river.

Basically, the study is based on manual on-screen mapping/digitization over high-resolution remote sensing data $(1 \mathrm{~m})$ available in Google Earth under very high magnification and field observations of some segments. Settlements/villages, and water ponds and tanks all along the course were also mapped to see if they exhibited any patterns indicating the existence of palaeo course of the Assi River. On-screen digitization was purely based on visual image impression and interpretation. To make sure that the results of mapping of palaeo river course of the Assi were consistent enough across various resolutions of remote sensing data, we used BHUVAN (1 m), CORONA aerial photographs (4 m), IRS-P6 LISS IV $(5.8 \mathrm{~m})$, Landsat-1 (60 m), Landsat-3 (30 m), Landsat-5 $(30 \mathrm{~m})$, Landsat-7 $(30 \mathrm{~m})$ and Landsat-8 $(30 \mathrm{~m})$ to map the palaeocourse of the Assi river between Allahabad and Varanasi. Further, SRTM (30 m) DEM was used to prepare cross-sectional profiles and Google Earth image to plot longitudinal profile along the mapped course. The impressions of the palaeochannel system were clear enough at some places, and where they were not visually clear, delineation was done through interpretation based on the settlement and water-pond patterns. There are no prepared datasets of any other kind available with precise information on the palaeochannels of the Assi river. There is no other way to delineate palaeochannels better than the remote sensing method, quickly and precisely. Remote sensing data are almost indispensable to delineate palaeochannels within floodplains ${ }^{1}$.

In the district Gazetteer of Varanasi ${ }^{13}$, the Assi has been described as a small monsoonal stream 3 miles (4.82 $\mathrm{km}$ distance as the crow flies) in length. The Assi with about $8 \mathrm{~km}$ length along its curvilinear channel (from a pond a little beyond Kardmeshwar) and a present catchment area of about $22 \mathrm{~km}^{2}$, is a small local stream. There are several disconnected channels/flow lines of the Assi within its catchment (Figure 1), and measuring along and through these gaps between the disconnected channels, its total length is about $11 \mathrm{~km}$. The first question about the Assi is whether it is a small stream or a river. Going by the length, catchment and a leaner flow, it is a small local stream/nala. The second question about the Assi is the place of its origin. As of now, the Assi collects its headwaters from Kanchanpur, Nathupur, Pahadi Gao, Ganeshpur, Kadipur, Lathiya, Amra Khaira Chak village areas north of National Highway No. 2 (NH-2) bypass (Figure 1). Before NH-2 bypass was constructed, there was a through flow into the Assi river from the area around Nuawan and Dafi. After construction of NH-2 bypass and other connected roads, waters from the southern part of the catchment immediately south and north of the bypass first get collected, concentrated and stagnated in the runnel (created along the elevated road) along the bypass and then flow into the Assi only when in excess so as to cause floods. In fact, under normal situation, this water concentrated in the runnel south and north of NH-2 bypass flows through pipes and passages to enter into other small streams south of the bypass (Figure 1). The catchment boundary of the present Assi has been delineated based on field observations during two rainy seasons (2016 and 2017). Further, about 5000 points collected within and around the Assi catchment with dual frequency differential global positioning system (DGPS; Leica make) in real time kinematic (RTK) mode are used to generate a DEM with $1 \mathrm{~m}$ cell size, using which the Assi catchment boundary is derived. There is no match
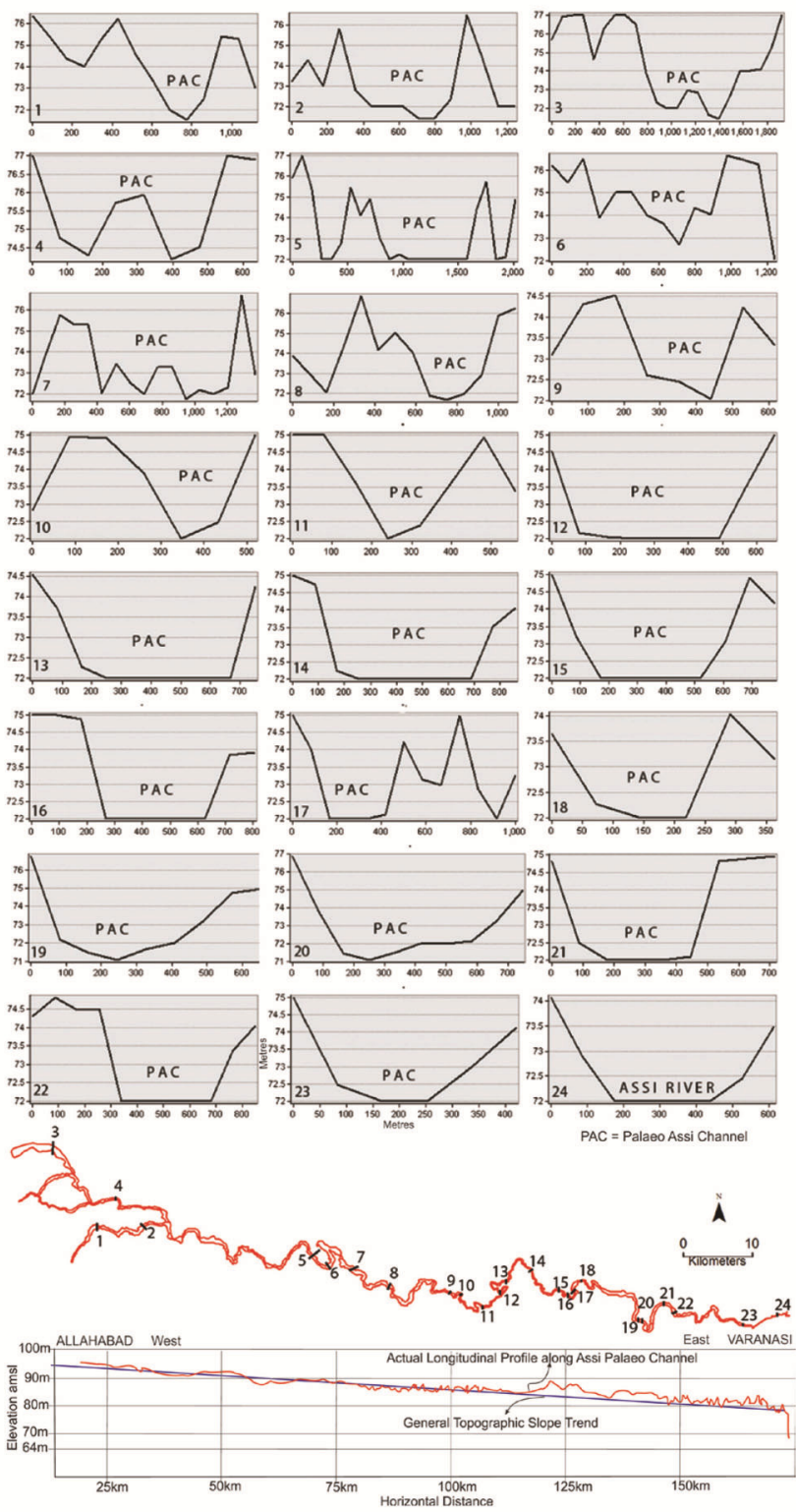

Figure 6. Cross-sectional profiles 1-24 (top) from SRTM 30 m DEM and longitudinal profile (bottom) along Assi palaeochannel (PAC) and index of cross profiles (middle).

CURRENT SCIENCE, VOL. 118, NO. 4, 25 FEBRUARY 2020 

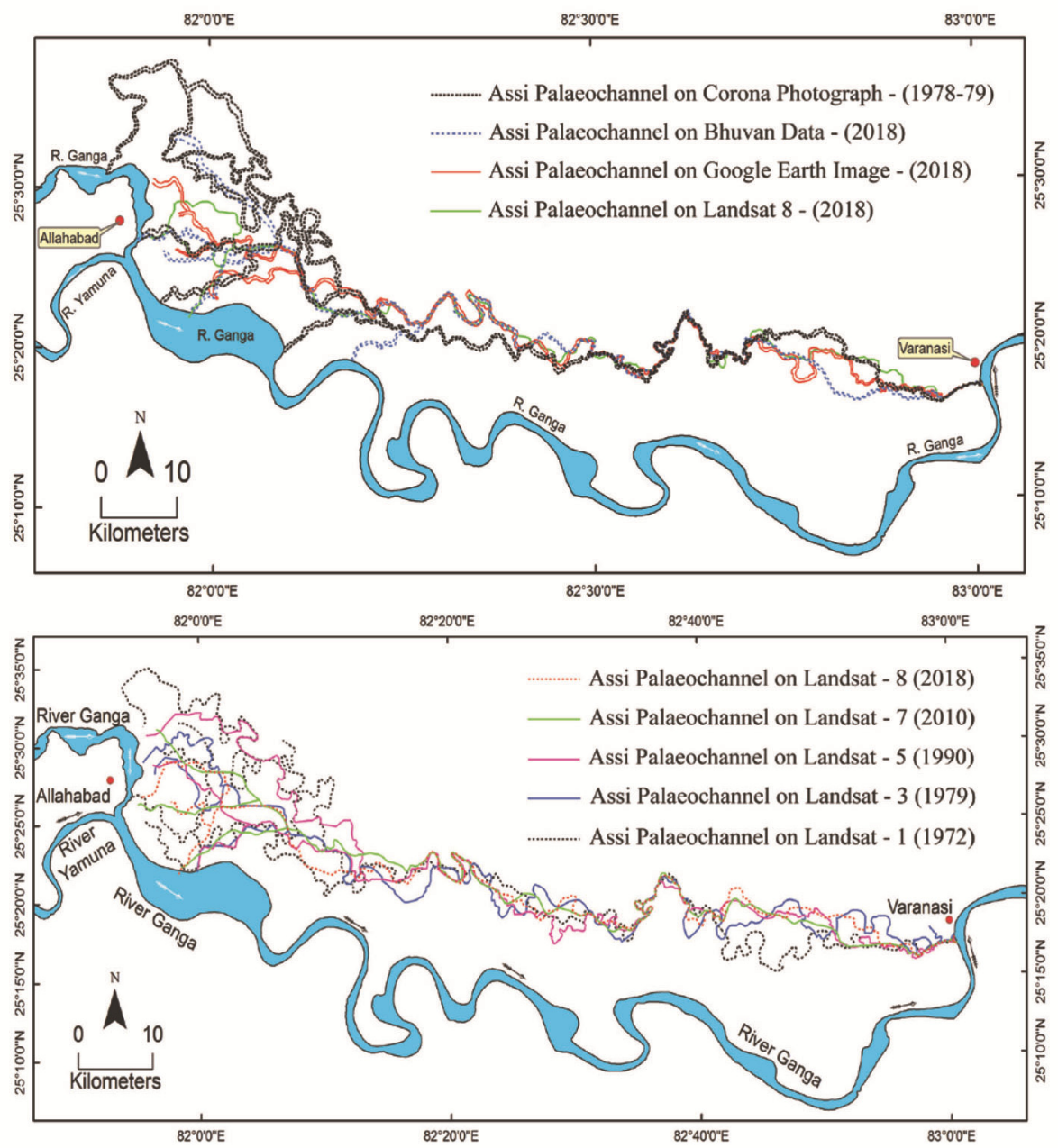

Figure 7. The Assi palaeochannel network from multi-temporal and multi-resolution remote sensing data.

between the two boundaries (Figure 1) because of the presence of several urban dykes in the form of high roads. At most places, the present Assi catchment boundary runs along the high roads.

While scanning through remote sensing data - IRS-P6 LISS IV, BHUVAN (Figure 2) and CORONA aerial photographs (Figure 3 ) - with a nominal resolution of 6,1 and $4 \mathrm{~m}$ respectively, we found a prominent segment of a buried channel about $10 \mathrm{~km}$ west of Varanasi city. Our first impression was that such curvilinear patterns could be reflections of crop cultivation within natural active flat stream beds in the plains, prevalent in many parts of India.

Going by the norm of 'spot field checks' to confirm doubts, the authors examined it in the field and found the buried channel segment to be devoid of any trace of an active stream. This led us to scan the remote sensing data further to find similar short, medium and long curvilinear segments of buried channels scattered between Allahabad and Varanasi. This encouraged us to find a continuous palaeochannel course (of a river) finally ending up into the present-day Assi (Figure 4). The distance as a crow flies between Allahabad and Varanasi is about $120 \mathrm{~km}$. This entire distance of $120 \mathrm{~km}$, the Google Earth image was scanned and through visual appreciation and interpretation all possible impressions of abandoned buried channels were digitized on-screen. Around $60 \mathrm{~km}$ of the $172-187 \mathrm{~km}$ course of the palaeochannel was clear enough and the rest of its length was interpreted based on the patterns of ponds and settlements and other image characteristics. One important image characteristic is a curvilinear strip showing patterned agricultural fields in dark green (natural colour) and red (false colour) colours within the channels with contrasting white sandy banks (light and white shades) occupied by human habitations and trees (in mottled rough texture) (Figures 2 and 3). Further, the settlements are spread in linear and curvilinear pattern as if they have developed and are situated along the banks of a river (Figure 4). Another strong proof in favour of the presence of a channel is the presence of abundant number of water ponds and tanks within the palaeo course showing linear shape and size conforming 


\section{RESEARCH COMMUNICATIONS}
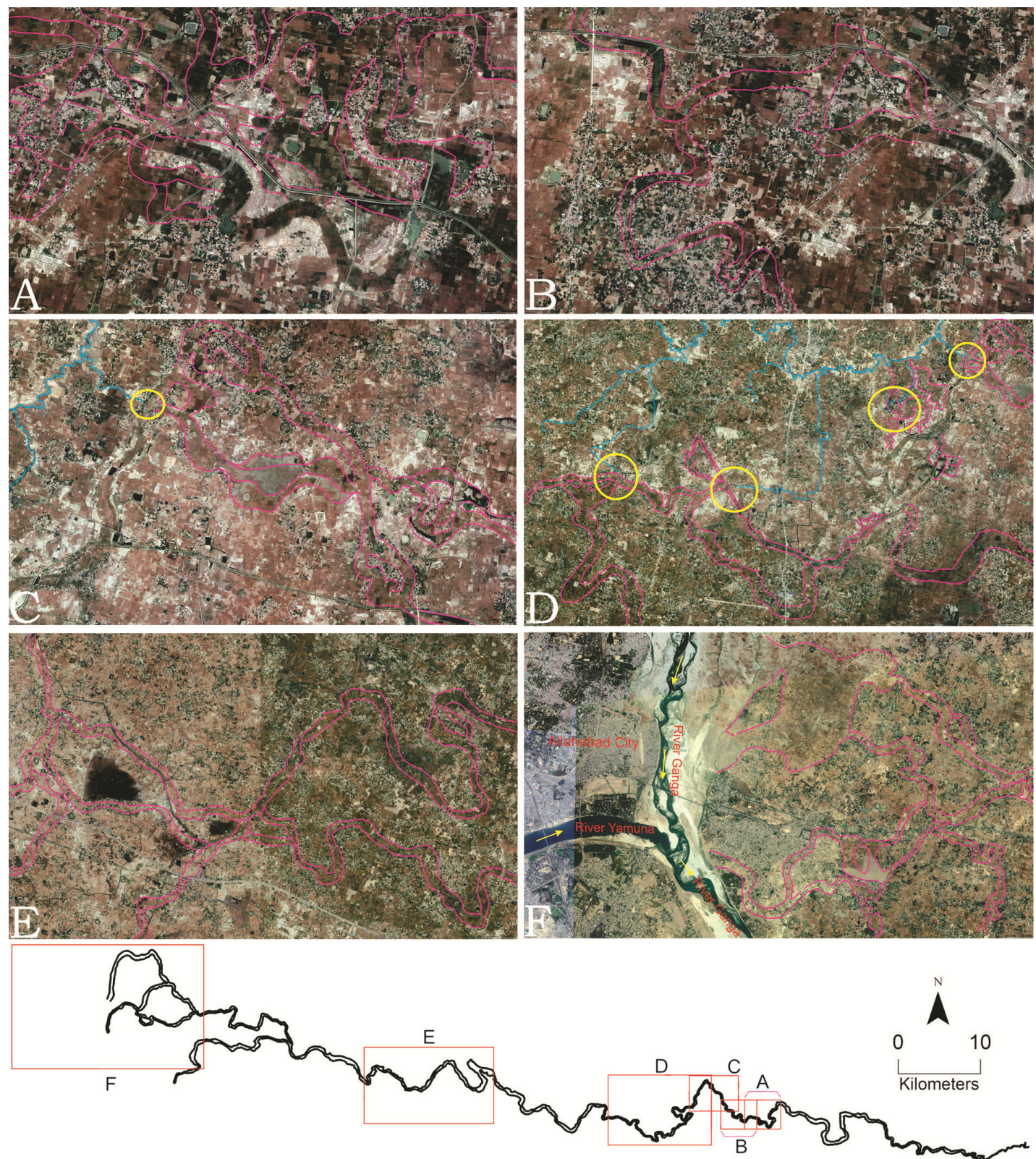

Figure 8. A to $\mathrm{F}$ are pieces of satellite image marked with Assi palaeo channel network (pink lines) and locations (yellow circles) of possible stream piracies by tributaries of Varuna river system (blue lines). Locations of A to F are shown at the bottom.

to the channel (Figure 5). The average width of this palaeochannel is about $200-300 \mathrm{~m}$, which is much more than any other floodplain tributary streams of the Varuna and Ganga rivers here between Allahabad and Varanasi. It is pertinent to point out here that all along the palaeocourse of the Assi river, the density of water ponds compared to the adjoining areas north and south of it is very high (Figure 5). Still, the cross-profiles taken across this palaeochannel in general exhibit central shallow depressions and higher ground on either side (Figure 6). Taking into consideration all the substantial supporting proof, we are convinced about the results of our image interpretation in tracing some major palaeochannels of the Assi river course. The general topographic slope along the course of this buried channel is from west to east (similar to the Ganga river here), with a fall of about $25-30 \mathrm{~m}$ of relief from the highest point $(95 \mathrm{~m}$ amsl) to the lowest point (between 60 and $70 \mathrm{~m}$ amsl) at the confluence of the Assi with the Ganga at Varanasi (Figure 6).

Most of the settlements are linear and curvilinear coinciding with the banks of the channels; and, most of the settlements are along the concave (cut-off) banks, the most favoured for the development of human habitations (Figure 4). There are ponds showing linearity and width equal to the width of palaeochannels. Most of the ponds within the channels show greater linearity than those 

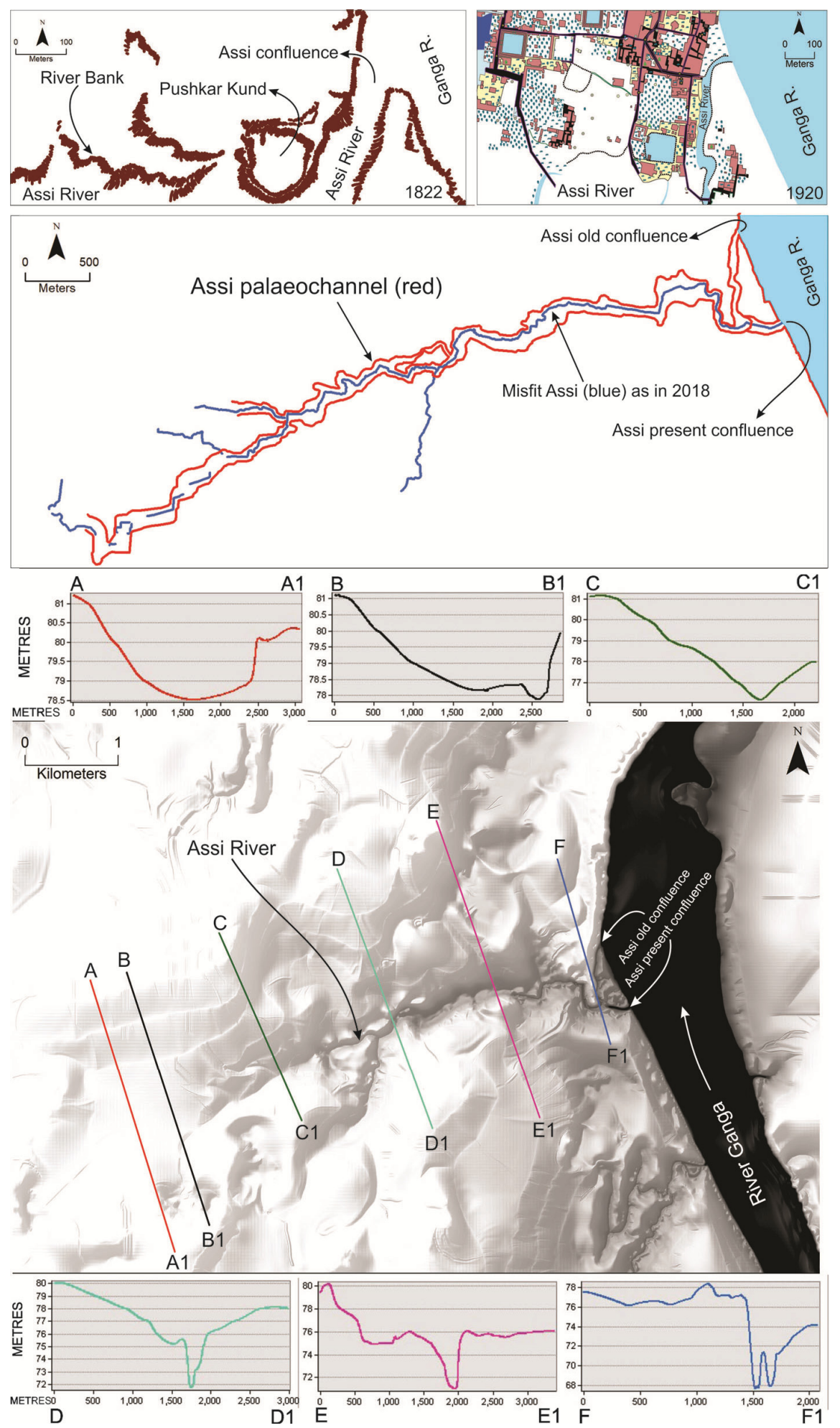

Figure 9. The Assi river confluence in 1822 as mapped by James Prinsep (top left) and in 1920 as mapped by C.H.D. Ryder (top right). (Middle) The Assi river as a misfit stream in a wide valley. (Bottom) DEM (1 m) of part of the present Assi river basin and cross profiles across the present Assi river.

away from the channels (Figure 5). The cross-profiles derived from DEM show clear depressions in comparison to the ground on either side of the mapped channel course (Figure 6). These depressions get filled during the rainy season. Figure 7 presents the palaeo course(s) of the Assi river delineated from various multi-temporal and multiresolution satellite datasets. Figure 8 shows remote sensing data at larger scales, with details of palaeochannel 


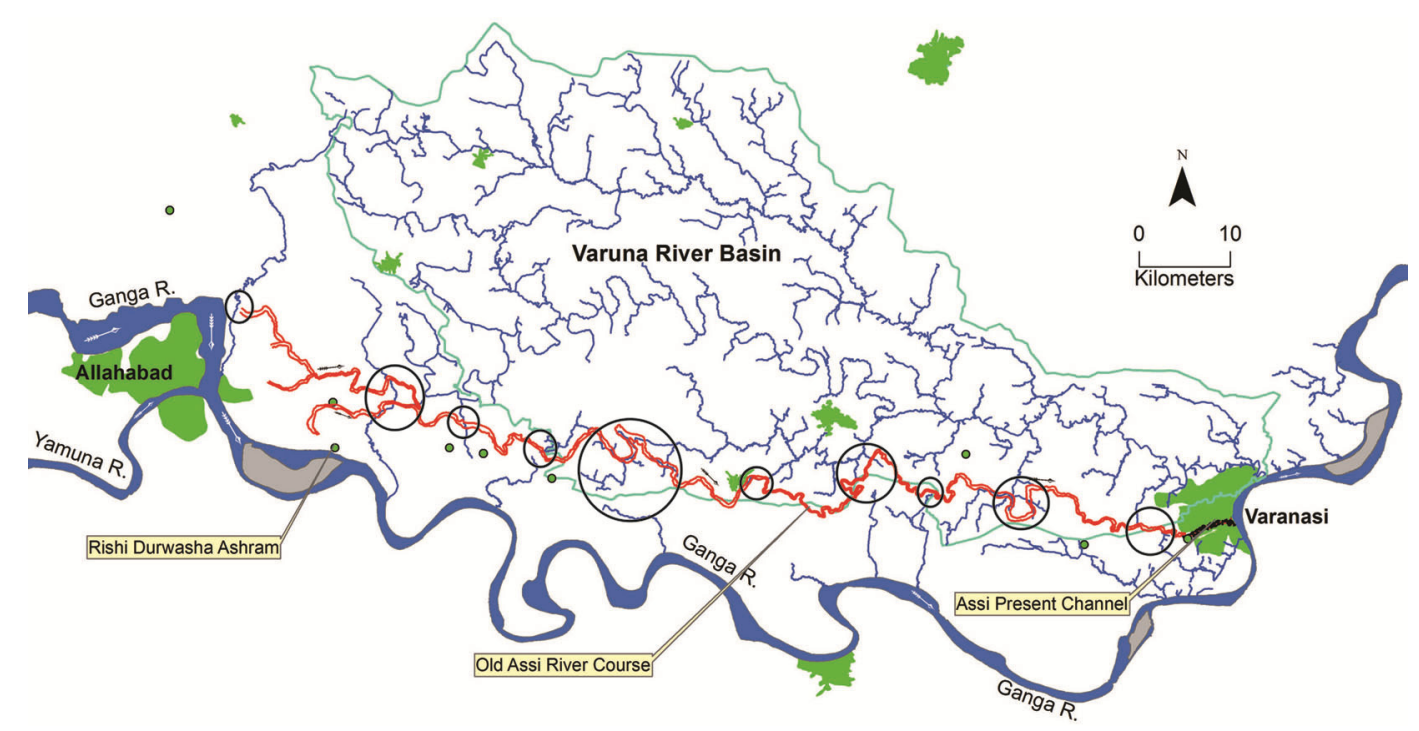

Figure 10. Map showing Ganga river stretch between Allahabad and Varanasi, the Varuna river system and its boundary, and the Assi palaeocourse (red). Black circles indicate possible locations of stream piracies by the Ganga-Varuna river system. Some major settlements are shown as green polygons (for names of settlements refer to Figure 1).

network marked over the same. Near Allahabad at the confluence of the Yamuna and the Ganga, there are clear impressions of several take-off channels from the Ganga joining to make up the Assi river (Figure 8).

When palaeochannel images are clear and convincing in remote sensing data, it can safely be concluded that there was a continuous active channel for a considerable period of time. If not independently as a tributary to the Ganga, the waters of the Assi appear to have taken-off from the Ganga River near Allahabad and/or the present location of Durawasa Rishi Ashram and flowed all along as a Yazoo stream to the Ganga. It may be noted that the palaeo Assi river channel is wider $(200-300 \mathrm{~m})$ than the present Varuna river channel (about $100 \mathrm{~m}$ wide at Varanasi with a catchment of about $3141 \mathrm{~km}^{2}$ ). Such a wide channel is possible only when there is a greater volume of flow; and, a greater volume of flow is possible only if the Assi flowed as a Yazoo stream/river into the Ganga. The width of the palaeo Assi channel near Allahabad and Rishi Durvasa Ashram is almost the same as that of its channel, although its length is an indication that the Assi river is probably not an independent tributary of the Ganga, but a Yazoo stream flowing parallel to the Ganga and joining the latter at Varanasi. Old maps of 1822 and 1920 showing wide channel mouths/confluences and about 100-250 $\mathrm{m}$ of valley width of the present-day misfit Assi are proof enough that the palaeo Assi river drained greater volume of water (Figure 9). Furthermore, the cross-profiles generated from $1 \mathrm{~m}$ DEM (prepared from about 5000 points collected with DGPS in RTK mode) and rendered with hill shade view, clearly show a wider channel of old Assi within which the present channel is now flowing as a misfit stream (Figure 9). At a later stage, the Assi might have turned into an independent river after direct take-off from the Ganga choked with sediments. After waters from the Ganga were cut-off, the flow must have turned leaner and the overland wash from either side and from the floodwaters of the Ganga may have gradually silted up the palaeo Assi channel, making it a misfit river in its earlier wider channel. Also, the fact that this palaeo course of the Assi river is visible on the surface clearly proves that it could be a feature of the recent past. Observing the wanderings and meanderings of the channel (Figure 7), it can be concluded that the palaeo Assi river flowed for a considerable period of time.

Now, the question regarding the palaeo Assi channel is, how and why did it disappear. There are four possibilities: (i) take-off channels from the Ganga were cut-off, (ii) sediment influx from higher level floodplains from either side of the Assi river and flood accretion deposits of the Ganga from the west and south choked the channel; (iii) piracy of tributaries by those of the Varuna in the north and of the Ganga in the south, and (iv) neotectonic disturbances. Though neo-tectonic disturbances are known within the Ganga plains, their signatures are not clearly visible to prove their role in the disappearance of the palaeo Assi river. However, active sedimentation at the Ganga-Yamuna confluence silting the palaeo Assi river take-offs appears most possibly the main reason for leaner contribution into the palaeo Assi river and its ultimate disappearance by the silt deposited by overland wash from either side. Stream piracies from the headward extending Varuna river tributaries and the Ganga (yellow circles in Figure 8 and black circles in Figure 10) appear to have also played an equally important role in capturing the waters and ultimate disappearance of the palaeo Assi river.

There are innumerable studies proving palaeochannels as good groundwater and rechargeable reservoirs, as the 


\section{RESEARCH COMMUNICATIONS}

channels essentially contain coarse sediments. Especially where the palaeochannels are contiguous with the active channels and where flood water collects in such palaeochannels, the groundwater potential is high. In the case of the Assi palaeochannel, most of the ponds/tanks within the channel do not dry up completely even though other ponds on either side go dry by February-March. Some waters in the ponds within the channel remain even during summer and the same ponds within the channel get replenished earlier than other ponds during the rainy season. Normally ponds have an inlet (from either a small local stream or a big river) and an outlet to remove excess water. Even nowadays during the rainy season, water collects in this palaeo Assi channel strip and to prevent the flooding of fields within this strip, a number of canals are taken out of this palaeo Assi river course. This is the first study of the palaeo course of Assi river presenting visual evidence from satellite data. This is also the first attempt to work out the present course and catchment of Assi through high resolution ( $1 \mathrm{~m}$ cell) digital elevation model and field mapping.

1. Prudhvi Raju, K. N., Remote sensing: status in Indian geography. In The Roots of Indian Geography: Search and Research (eds Singh, R. L. and Singh, R. P. B.), The National Geographical Journal of India, The National Geographical Society of India, Varanasi, 1992, vol. 34, pp. 195-204.

2. Wray, R. A., Palaeochannels of the Namoi River Floodplain, New South Wales, Australia: the use of multispectral Landsat imagery to highlight a Late Quaternary change in fluvial regime. Austr. Geogr., 2009, 40(1), 29-49; https://doi:10.1080/000491808026$\underline{56952 .}$.

3. Karmanov, V. N., Chernov, A. V., Zaretskaya, N. E., Panin, A. V. and Volokitin, A. V., Palaeochannel studies in archaeology: the case of the Vychegda River, northeastern European Russia. Archaeol. Ethnol. Anthropol. Eurasia, 2013, 41, 83-93; http://doi:10.1016/j.aeae.2013.11.008.

4. Ghose, B., Pandey, S., Singh, S. and Lal, G., Geomorphology of the Central Luni Basin, Western Rajasthan. Ann. Arid Zone, 1966, $\mathbf{5}(1), 10-25$.

5. Ghose, B., Kar, A. and Husain, Z., The lost course of the Sarasvati river in the Great Indian Desert: new evidences from Landsat imagery. Geogr. J. London, 1979, 145(3), 446-451.

6. Yash Pal, Baldev, S., Sood, R. K. and Agarwal, D. P., Remote sensing of 'lost' Sarasvati. Proc. Indian Acad. Sci. (Earth and Planet. Sci.), 1980, 89(1), 317-331.

7. Rajawat, A. S., Verma, P. K. and Nayak, S., Reconstruction of palaeodrainage network in northwest India: retrospect and prospects of remote sensing based studies. Proc. Indian Natl. Sci. Acad., Part A, 2003, 69(2), 217-230

8. Radhakrishna, B. P. and Merh, S. S. (eds), Vedic Saraswati: Evolutionary History of a Lost River in North-west India, Geological Society of India, Bengaluru, Memoir 42, 2002, pp. 1-327.

9. Qunghai, X., Chen, W., Xuanqing, Z. and Xiaolian, Y., Palaeochannels on the North China plain: stage, division and palaeoenvironment. Geomorphology, 1996, 18, 15-25.

10. Kumar, H. and Rajawat, A. S., Potential of RISAT-1 SAR data in detecting palaeochannels in parts of the Thar Desert, India. Curr. Sci., 2017, 113(10), 1899-1905.

11. Jana, S., Mohanty, W. K., Gupta, S., Rath, C. S. and Patnaik, P., Multi-pronged search for palaeo-channels near Konark Temple, Odisha-implications for the mythical river Chandrabhaga. Curr.
Sci., 2018, 115(2), 300-309; http://doi:10.18520/cs/v111/i8/13871393.

12. Gautam, A. M., Application of IRS-1A data for delineating buried channels in southern part of Allahabad district of Uttar Pradesh. Photonirvachak J. Indian Soc. Remote Sensing, 1990, 18(3), 5255.

13. Joshi, E. B., Gazetteer of India, Uttar Pradesh District, Varanasi, Department of District Gazetteer, Government of Uttar Pradesh, Lucknow, 1965, pp. 7-8.

ACKNOWLEDGEMENTS. We thank Dr Y. V. N. Krishna Murthy (former Director, National Remote Sensing Centre (ISRO), Hyderabad) for motivation and guidance. M.M. thanks University Grants Commission, New Delhi for awarding a Junior Research Fellowship (3043/NET-JUNE 2014). We thank Google Earth and BHUVAN for their high-resolution satellite data and mapping tools used in the present study.

Received 7 April 2019; revised accepted 13 November 2019

\section{Influence of different sources and methods of potassium application on the quality of grapes cv. Sharad Seedless (Vitis vinifera L.)}

\author{
Y. Pushpavathi ${ }^{1 * *}$, J. Satisha ${ }^{1}$, G. C. Satisha ${ }^{1}$, \\ K. S. Shivashankara ${ }^{1}$, M. Lakshminarayana \\ Reddy $^{2}$ and S. Sriram ${ }^{1}$ \\ ${ }^{1}$ ICAR-Indian Institute of Horticultural Research, Hesaraghatta, \\ Bengaluru 560 089, India \\ ${ }^{2}$ Dr Y.S.R. Horticultural University, Venkataramannagudem 534 101, \\ India
}

Potassium is often considered as the quality element for crop production. Grapevine is one of the most potassium-friendly plants that has a better ability to utilize soil potassium. Grape berries are a strong sink for potassium, particularly during ripening. To ascertain the influence of the combined application of different sources and methods of potassium application on the quality of grape cv. Sharad Seedless, an experiment was conducted at Indian Institute of Horticultural Research, Bengaluru during two consecutive years, viz. 2016-17 and 2017-18 with three different sources of potassium fertilizers (SOP, $\mathrm{KNO}_{3}$ and $19: 19: 19$ ), and two methods of application (soil application and fertigation). Pooled analysis revealed that among the treatments, grapevines treated with sulphate of potash as $60 \%$ through fertigation and

\footnotetext{
*For correspondence. (e-mail: pushpayaruva@gmail.com)
} 